\title{
Beneficial Effect of Quercetin Against Dimethoate Induced Cerebellar Cortex Injury in Adult Male Albino Rat: Histological and Immunohistochemical Study
}

\author{
AMIRA E. ALSEMEH, M.D.; EMAN M.A. ABDELGHANY, M.D. and NANCY H. HASSAN, M.D.
}

The Department of Human Anatomy and Embryology, Faculty of Medicine, Zagazig University, Egypt

\begin{abstract}
Background: The organophosphorus compound dimethoate is pesticide that widely used across the world to control worms and insects. It is highly toxic and causes neurobehavioral disorders. Quercetin is a natural flavonoid that is profusely found in fruits and vegetablesand is known for its antioxidants property and its ability to improve oxidative stress and promote cellular survival.
\end{abstract}

Aim of Study: To assess neurotoxicity and structural alterations of cerebellar cortex caused by dimethoate and explore the neuroprotective potential effect of quercetin.

Material and Methods: The study was carried out on 32 adult, male Wister albino rats weighing $180-200 \mathrm{~g}$, they were randomly divided into four groups: Normal control, dimethoate treated $(30 \mathrm{mg} / \mathrm{kg}$ alternate day), quercetin treated $(50 \mathrm{mg} / \mathrm{kg}$ daily) and combined dimethoate + quercetin treated. All the treatments continued for 60 days. All animals were anesthetized, cerebellum was removed to prepare the specimens for histological, immunohistochemical and biochemical examination.

Results: The results revealed asign of toxicity and a significant decrease in body weight of animals treated with dimethoate which were substantially improved upon concurrent supplementation with quercetin. Further, treatment with dimethoate resulted in a significant decrease in the activity of acetyl cholinesterase in cerebellum tissue which was increased upon co-treatment with quercetin. On the contrary, we noticed a significant increase in the levels of MDA in cerebellum which were revealed significant reduction upon supplementation of quercetin. Light microscopic examination of cerebellum showed histoarchitectural alterations with significant up regulation of apoptotic marker (caspase-3) and astrogliosis marker Glial Fibrillary Acidic Protein (GFAP) in cerebellar tissue, Although, there were a significant down regulation of synaptophysin (SYP) immunoexpression. These changes were improved upon co-treatment with quercetin. Therefore, we conclude that quercetin when used as a prophylactic intervention would afford safeguard against dimethoate induced neurotoxicity.

Correspondence to: Dr. Amira E. Alsemeh, E-Mail: Dr Amira 2008@yahoo.com.
Key Words: Quercetin-Dimethoate-Cerebellar Cortex.

\section{Introduction}

ORGANOPHOSPHORUS pesticides (OP) are chemical agents that are used worldwide to control insects and worms. It is used to increase agricultural production and to enhance the quality and quantity of the product. Pesticide particles have been found everywhere in atmosphere and they present in high concentrations particularly in the areas where they are used. They affect both central and peripheral nervous system and can cause neurological disorders [1]. The Dimethoate insecticide is one of the most used OP in United States and throughout the world. Dimethoate is used in agriculture, veterinary practice and as ectoparasitic ide applied against human body lice [2].

The acute neurotoxic mechanism of action of Dimethoate is typically cholinergic. It involves an inhibition of the Acetylcholinesterase (AChE) of the neuronal tissue through its active metabolic form, the Omethoate which turns out to be 10 times as toxic as the Dimethoate. The Omethoate rapidly binds to the hydroxyl group of the active site of $\mathrm{AChE}$, and undergoes a double displacement reaction involving the serum hydroxyl groups and dimethyl phosphorylated from AChE. Inhibition of AChE causes an accumulation of acetylcholine released in the synaptic cleft. As a result, hyper-

\footnotetext{
Abbreviation:

OP : Organophosphorus pesticides.

SYP : Synaptophysin.

GFAP : Glial Fibrillary Acidic Protein

PCL : Purkinje Cell Layer.

MCL : Molecular Cell Layer.

GCL : Granular Cell Layer.
} 
stimulation of the nicotinic and muscarinic receptors is induced. Thus, the passage of nerve information is disrupted [3]. Furthermore, the oxidative stress caused by the peroxidation of lipids and favored by the dimethoate is considered as another mechanism of toxicity of this organophosphorus compound [4-6]. Toxic effects of OP include genotoxicity, hepatic dysfunction, embryotoxicity, teratogenicity, neurochemical, and neurobehavioralchanges [7]. It was reported that both acute and chronic exposures to chlorpyrifos (CPF) resulted in liverdamage in rats [8-10]. Furthermore, acute and subchronic exposures to dimethoate caused pathological changes in the brain and liver of rats $[11,12]$.

Although the acute and sub-chronic physical effects of dimethoate exposure are well documented $[13,14]$, there are a limited number of studies describing the neurobehavioral deficits caused by this organophosphorus compound.

Quercetin is one of the most frequently studied bioflavonoids in its class of flavanols. It occurs naturally in a variety of brightly colored plantbased foods as glycosides linked to glucose, galactose, xylose and rhamnose. Quercetin is present in high concentrations in fruits and vegetables such as tea, apples, mulberries, onions, potatoes, broccoli, soybeans, peanuts, and red wine. It has been shown to have highly potent antioxidant and cytoprotective effects in preventing endothelial apoptosis caused by oxidants [14]. Quercetin is a more potent antioxidant than other antioxidant nutrients, such as vitamin $\mathrm{C}$, vitamin $\mathrm{E}$, and $\beta$-carotene, and it can chelate transition metal ions, including iron, thus preventing the iron-catalyzed Fenton reaction $[15,16]$.

Quercetin is considered to be a strong antioxidant because of its ability to scavenge free radicals and to bind to transition metal ions. The antioxidant character of quercetin is associated with the presence and location of hydroxyl (-OH) substitutions and the catechol-type B-ring $[17,18]$. Quercetin has been shown to inhibit pro-inflammatory enzymes such as cyclooxygenase and lipoxygenase, thereby reducing the production of inflammatory mediators like leukotrienes and prostaglandins [19]. However, the information is lacking with regard to protective effects of quercetin, against the neurotoxic effects of dimethoate on rat cerebellum.

Therefore, the present study was conducted to explore whether quercetin affords protection against dimethoate induced neurotoxicity in rats.

\section{Matrial and Methods}

\section{Animals:}

Thirty-two healthy adult male Wistar albino rats (12-14 weeks) weighing 180-200g were gained and preserved at the Breeding Animal House of the Faculty of Medicine, Zagazig University from February 2019- April 2019. Animals were maintained for acclimatization in disconnected hygienic stainless-steel cages at a controlled temperature $\left(23 \pm 2{ }^{\circ} \mathrm{C}\right)$ and humidity $(60 \pm 5 \%)$ in a $(12: 12 \mathrm{~h}$ light: Dark cycle) synthetically enlighten room, completely free from chemical contagion. All rats were fed with the standard laboratory chew diet and had free access to water. All experimental animals adapted to laboratory condition for ten days prior to the beginning of experiments. All used protocols were in accordance with Ethical Committee of Zagazig University that is in accordance with the NIH Guidelines for the Care and Use of Laboratory Animals.

\section{Material:}

Chemicals:

Dimethoate, technical grade of $97 \%$ purity and Quercetin dihydrate were purchased from Sigma Aldrich Chemical Company. Other chemicals used in this study were of analytical grade and were obtained from the local firms. The acute oral LD50 of dimethoate for rat used in the present study is $150 \mathrm{mg} / \mathrm{kg}$ according to WHO (2009). Dimethoate is classified as moderately hazardous [20]. Dimethoate was dissolved and diluted to the required doses using distilled water.

\section{Methods:}

\section{Experimental design:}

The animals were randomly divided into four groups with 8 rats in each group as follow:

Control group: The animals in this group received distilled water.

Quercetin group: The animals in this group were given quercetin every day in the form of quercetin hydrate orally by gavage at a dose of $50 \mathrm{mg} / \mathrm{kg}$ body weight for 60 days. 1 gram of quercetin powder was dissolved in $100 \mathrm{ml}$ distilled water. So, each milliliter of the solution contained $10 \mathrm{mg}$ of quercetin. Therefore, each rat was administered $0.80-1 \mathrm{ml}$ of hydrated quercetin [21].

Dimethoate group: The animals in this group were given oral (by gavage) a dose equal to $1 / 5$ LD50 $(30 \mathrm{mg} / \mathrm{kg})$ of dimethoate alone every alternate day for 60 days (Total of 30 Treatments). $1 \mathrm{ml}$ of dimethoate solution had $0.97 \mathrm{~g}=970 \mathrm{mg}$ of dimeth- 
oate which was dissolved in $485 \mathrm{ml}$ of distilled water. So, each $\mathrm{ml}$ contained $2 \mathrm{mg}$ of dimethoate, so each rat was administered $3-2.8 \mathrm{ml}$ of dissolved dimethoate [20].

Dimethoate + quercetin group: The animals in this group were given a combined treatment with dimethoate $(30 \mathrm{mg} / \mathrm{kg})$ concomitant with quercetin $(50 \mathrm{mg} / \mathrm{kg})$.

\section{Record of body weights:}

At the end of the experiment, the body weight of all rats was recorded by digital electrical balance (Sartorius Goettingen type 140/AG,W. Germany).

Twenty-four hours, animals were anesthetized with intraperitoneal injection of thiopental $50 \mathrm{mg} / \mathrm{kg}$ body weight [22]. Afterward, careful craniotomy was performed not to cut through the brain and the vault of each animal cranium was removed. After freeing the brain from meninges, it was gently lifted out of the skull. Small forceps was placed between the cortical lobes and the cerebellum and the cerebellum was snapped off from the inferior colliculus. Then the cerebellum was gently divided into two halves. The first half was fixed in $10 \%$ paraformaldehyde for 24 hours and processed for examination by light microscope. The other half was frozen immediately on dry ice, stored at-80c for biochemical analysis to evaluate the oxidative stress biomarkers and Acetylcholine esterase (Ach E) activity.

Tissue preparation for lipid peroxidation and acetylcholine esterase ( $A$ ch $E$ ) assay:

Specimens were minced and homogenized $(10 \%$ W/V) separately in ice-cold saline, sucrose buffer $(0.25 \mathrm{M}$ sucrose, $1 \mathrm{mM}$ EDTA and $0.05 \mathrm{M}$ Tris- $\mathrm{HCl}$, $\mathrm{pH}$ 7.4) in a Thomas Sci. Co. glass-type homogenizer (Teflon pestle). The homogenization of tissues was carried out in Teflon-glass homogenizer with a buffer containing $1.15 \% \mathrm{KCl}$ to obtain $1: 10$ $(\mathrm{W} / \mathrm{V})$ whole homogenate. Centrifugation of half of the homogenate was done at $3000 \mathrm{rpm}\left(+4{ }^{\circ} \mathrm{C}\right)$ for $15 \mathrm{~min}$ to determine Malondialdehyde (MDA), MDA is detected as the end-product of lipid peroxidation Malondialdehyde (MDA) was assayed according to the method proposed by Ohkawa et al., [23]

The other half of the homogenate was centrifuged at $5000 \mathrm{rpm}$ for $50 \mathrm{~min}$ to measure Acetylcholine esterase (Ach E) activity. The levels of acetylcholine esterase were estimated by using the method of Ellman et al., [24,25]

\section{Tissue preparation for histopathological studies.}

1-Representative specimens from the cerebella were immediately fixed in $10 \%$ neutral buffered formalin for $24 \mathrm{~h}$, washed and dehydrated with conventional ascending grade of alcohol, cleared in xylol, then embedded in paraffin. Then, 5 m a thick sections were stained with haematoxylin and eosin (H\&E) according [26] for studying the histopathological changes of the cerebellar cortex in all studied groups.

For immunohistochemical analysis, deparaffinized and hydrated sections were incubated for 20 min at $105^{\circ} \mathrm{C}$ in Citrate buffer (pH 6.0) for antigen retrieval of the following proteins.

2- Anti-cysteine Aspartic Acid Specific Protease anti body (Caspase-3): Caspase-3 is a marker for apoptosis known to be increased in neurodegenerative diseases. Rabbit monoclonal antibody of $\mathrm{IgG}$ type against caspase 3 (dilution 1:100) delivered from Lab Vision Laboratories. Apoptotic cells observed with yellow to brown discoloration [27]

3- Anti-Glial Fibrillary Acidic Protein antibody (GFAP): GFAP immune staining is the most commonly used method to examine the distribution of astrocytes and their response to neural degeneration or injury [28]. The modified Avidin - Biotin immuno - peroxidase technique for glial fibrillary acidic protein (GFAP) was applied to demonstrate astrocytes. Primary anti GFAP antibody goat polyclonal $\mathrm{IgG}$, anti-rat produced by DakoCytomation was used. Working dilution was 1:1000. GFAP containing cells (astrocytes) appeared brown [29]. The positive results were indicated by brown coloration of the cell membrane and cytoplasm of the astrocytes. All stained slides were analysed by light microscopy (LEICA ICC50 W) in Image Analysis Unit of Anatomy and Embryology department.

4- Anti-synaptophysin (SYP) antibody: SYP a reliable marker for axonal damage. Sections were incubated with the primary antibody, rabbit polyclonal antibody Ab-4 (1:200, Lab Vision Corporation, Fremont, CA); overnight at $4{ }^{\circ} \mathrm{C}$. The marker was immunohistochemically localized using $\mathrm{ABC}$ peroxidase method where secondary polyclonal antibody formed of biotinylated anti-polyvalent antibody, streptavidin peroxidase and 3,3' diaminobenzidine was applied. Localization was visualized with 3,3'-diaminobenzidine and counter-stained in Meyer's hematoxylin, dehydrated, and mounted [30].

Negative control sections were performed with the same procedure mentioned before except that the primary antibody was replaced by non-immune 
goat serum. Antibodies were diluted with $0.5 \%$ casein in phosphate buffered saline before application [26].

\section{Morphometrical analysis:}

For morphometrical study, 8 rats were utilized per group by using image analyser (the Image $\mathbf{J}$ software plugin) in Anatomy Department, Zagazig University as follow:

1-Percepetive H\&E stained slides of each group were analysed to measure the thickness of all layers of the cerebellar cortex ( $\mathrm{m}$ ):-Molecular cell layer (MCL), Purkinje cell layer (PCL) and granular cell layer (GCL).

2- Perceptive Caspase-3 immunohistochemical stained slides of each group were analysed for calculating the immunopositively cells by using point selection at the objective lens of 40x.

3- Perspective GFAP immunohistochemical stained slides of each group were analysed for to estimate the area percentage of positive immune reaction for GFAP, which was done after image splitting. Images were split into RGB stacks then red stack was adjusted to threshold to mark it with a binary mask. Then the percent area in relative to the field was calculated at the objective lens of 40x.

4- Perspective Synaptophysin immunohistochemical stained slides of each group were analysed for to estimate the area percentage of positive immune reaction for Synaptophysin, which was done after image splitting. Images were split into RGB stacks then red stack was adjusted to threshold to mark it with a binary mask. Then the percent area in relative to the field was calculated at the objective lens of 40x.

\section{Statistical analysis:}

Continuous variables were expressed as the mean \pm SD as the data exhibited normal distributions (parametric). Normality was checked by the Kolmogorov-Smirnov test. One-way ANOVA was used to detect significant differences between groups. Post hoc Tukey's test was performed for multiple comparisons between groups. The differences were considered significant at $p<0.05$. All statistical calculations were carried out using Graph pad Prism software, version 5.0 (Graph Pad Software, San Diego, CA, USA).

\section{Results}

The control group and quercetin group showed no significant differences between them in body weight, biochemical changes or histological chang- es; therefore, they were considered as one group, called the control group.

\section{General physical signs:}

Signs of systematic toxicity on dimethoate exposure at dosage $30 \mathrm{mg} / \mathrm{kg}$ such as irritability, erected furs, suspended tail, itching, startle response, and crawling gait due to splay of the hind limbs were observed. In addition, loss of weight due to decrease of food grip and increase in the bowl movement were recorded and this continued to the end of the experiment. After two weeks of dimethoate administration, two rats died and they were replaced. In contrary. Co-administration with quercetin resulted in reduced irritability, erected furs, and startle response. The rats were normal in their gait, feeding and bowel movement. There is no mortality in this group. The body weights of dimethoate +quercetin treated rats were significantly increased compared to dimethoate received group (Fig. 1).

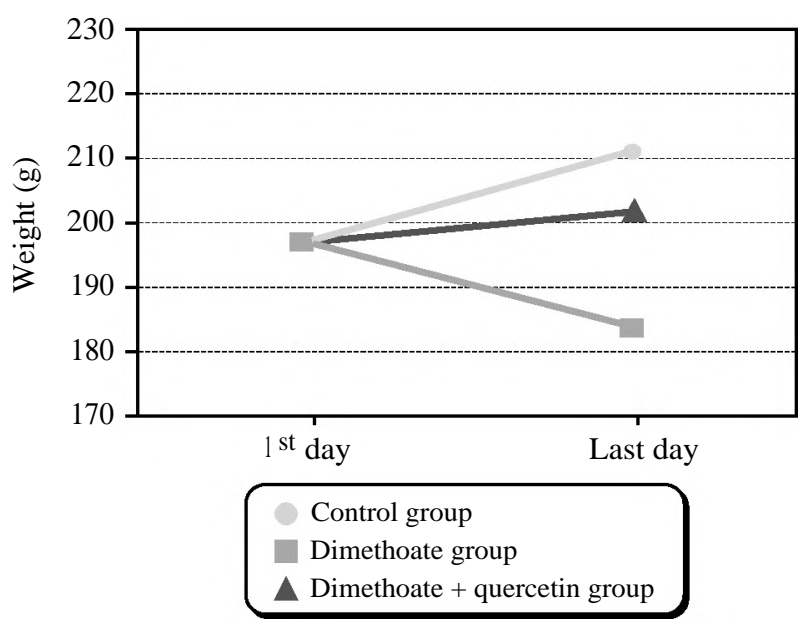

Fig. (1): A Histogram shows the mean weight in grams in different experimental groups

\section{Lipid peroxidation marker:}

The current results revealed an increase of lipid peroxidation in the cerebellar cortex of dimethoate treated group as evidenced by increase of malondialdehyde (MDA) levels in the cerebellar cortex homogenate extract when compared to control group. Indimethoate + quercetin, treated group lipid peroxidation sings were alleviated without reaching normal values (Fig. 2).

\section{Acetylcholine esterase activity:}

Rats received dimethoate showed a significant inhibition of AChE activity compared to control group. The co administration of dimethoate and quercetin resulted in significant increase in of $\mathrm{AChE}$ activity compared dimethoate group, without reaching the normal values (Fig. 3). 


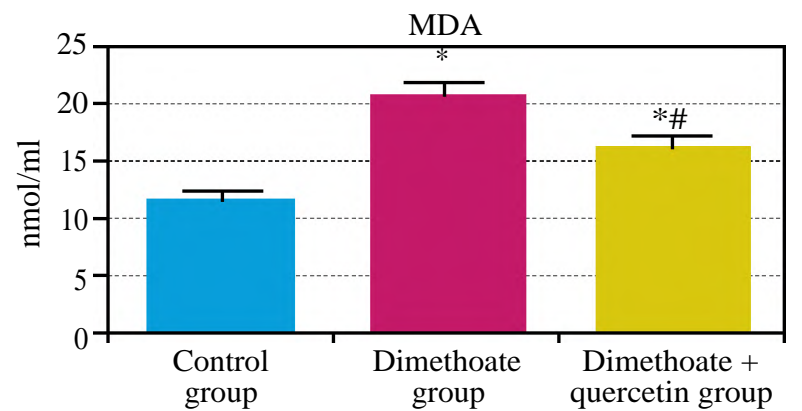

Fig. (2): Bar charts showing the changes in the activity of MDA in control, dimethoate treated group and dimethoate + quercetin treated groups. Statistical analysis was performed using one-way ANOVA, followed by Tukey's post hoc test. Values are represented as the mean $\pm \mathrm{SE}(\mathrm{n}=8)$. \# Significant difference compared to the control group, $p<0.05$. *Significant difference compared to the Dimethoate group, $p<0.05$.

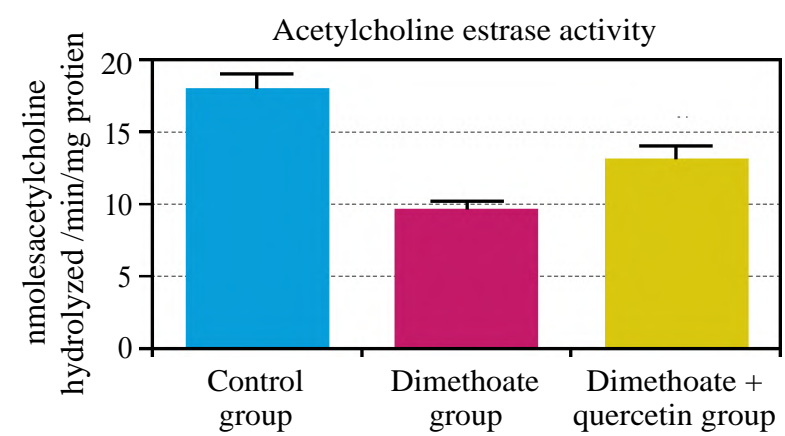

Fig. (3): Bar charts showing the changes in the mean values of the Acetylcholine esterase level in control, dimethoate treated group and dimethoate + quercetin treated groups. Statistical analysis was performed using one-way ANOVA, followed by Tukey's post hoc test. Values are represented as the mean $\pm S E(n=8)$. \#Significant difference compared to the control group, $p<0.05$. *Significant difference compared to the Dimethoate group, $p<0.05$.

\section{Histopathological results (hematoxylin and eosin staining):}

In control group: H\&E stained sections showed normal architecture of cerebellar cortex that is formed of three successive layers. The outermost was the molecular layer; the middle was the Purkinje cell layer which appeared flask shaped with apical dendrites, arranged in one row, characterized by pale basophilic cytoplasm and a central vesicular nucleus with prominent nucleoli; while the granular layer was the innermost that contained closely packed granule cells and cerebellar islands between them (Fig. 4).

In dimethoate group: $\mathrm{H} \& \mathrm{E}$ stained sections revealed degenerated Purkinje cells, with darkly stained cytoplasm and nuclei. Halos of empty spaces (vacuolations) around degenerated Purkinje cells were also detected. The Molecular layer showed empty spaces. Cells of the granular layer showed darkly stained nuclei with spaces between them (Fig. 5).

In dimethoate + quercetin treated group: $\mathrm{H} \& \mathrm{E}$ stained sections showed that most of Purkinje cells retained their normal characters and few with dark stained cytoplasm and dark pyknotic eccentric nuclei. Few halo of empty spaces (vacuolations) around shrunken Purkinje cells were noticed. Few empty spaces in molecular and granular layers could be also detected (Fig. 6).

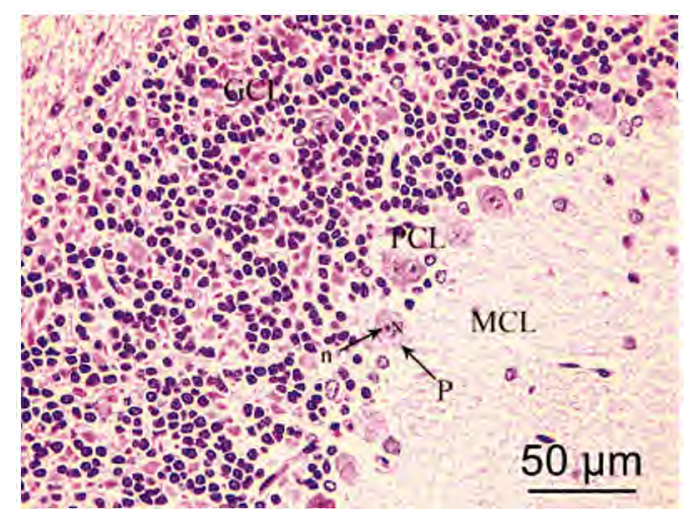

Fig. (4): A photomicrograph of the cerebellar cortex of the control group shows the three layers of the cerebellar cortex; molecular cell layer (MCL), Purkinje cell layer (PCL), and Granular cell layer (GCL). The Purkinje cell (P), contains large nucleus $(\mathrm{N})$ with prominent nucleolus (n). H\&E x $50 \mu \mathrm{m}, \mathrm{x} 400$.

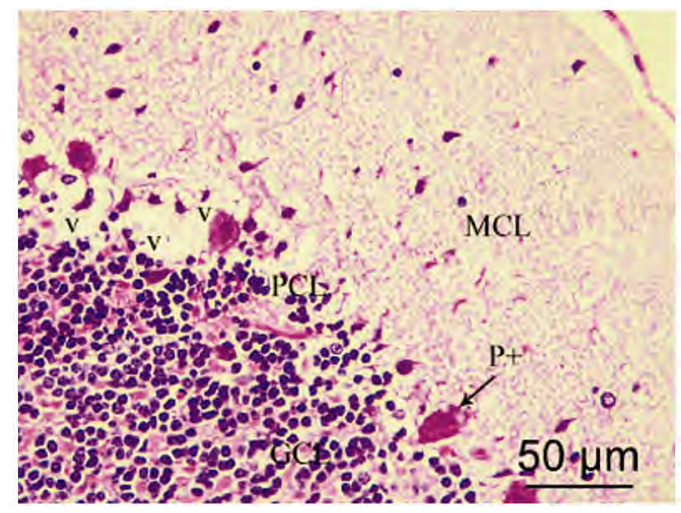

Fig. (5): A photomicrograph of the cerebellar cortex of the Dimethoate treated group shows the three layers of the cerebellar cortex; molecular cell layer (MCL), Purkinje cell layer (PCL), and Granular cell layer (GCL). The Purkinje cell (P+) is necrotic, and lost in many regions with multiple areas of vacuolations (V). H \& E x $50 \mu \mathrm{m}, \mathrm{x} 400$

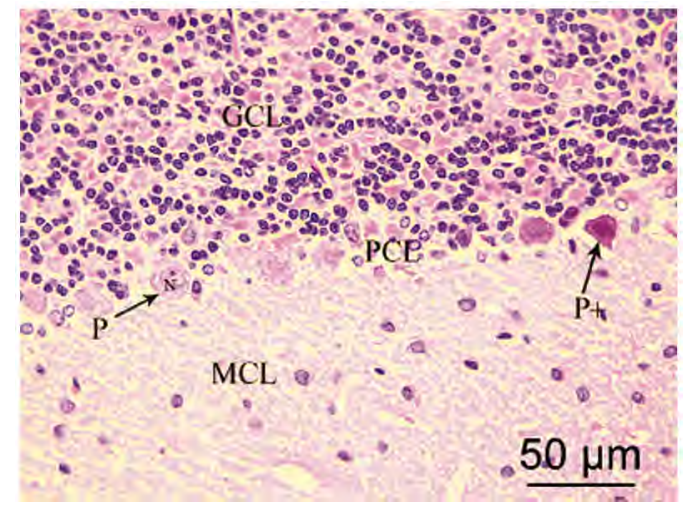

Fig. (6): A photomicrograph of the cerebellar cortex of the Dimethoate + Quercetin treated group shows the three layers of the cerebellar cortex; molecular cell layer (MCL), Purkinje cell layer (PCL), and Granular cell layer (GCL). Most of the Purkinje cells (P) are keeping their normal character with large nucleus $(\mathrm{N})$, with few necrotic ones $(\mathrm{P}+)$ and lost in some regions. H \& E x $50 \mu \mathrm{m}, \mathrm{x} 400$. 
Immuno-histochemical results:

\section{Caspase-3:}

The cerebellar cortex was stained immunohistochemically with anti-caspase 3 antibody to illuminate the localization of apoptotic neurons in all experimental groups. The immune positive reaction was localized in the cytoplasm of apoptotic neurons. In the control group the neurons exhibited negative immunoreaction especially in the PCL of the cerebellar cortex (Fig. 7a). However, in the dimethoate treated group, obvious caspase immunopositive neurons with appearance of dark brown stained areas especially PCL were detected (Fig. 7b). Whereas fewer caspase3 immunopositive neurons were observed especially in the PCL of dimethoate+quercetin group (Fig. 7c). These results confirmed statistically where dimethoate treated group exhibited significant up regulation of caspase-3 apoptotic marker compared to control group. However, in dimethoate + quercetin treated group revealed significant down regulation of caspase3 apoptotic marker compared to dimethoate group but still exhibited significant difference from the control as presented in (Fig. 7d).

\section{Glial fibrillary acidic protein (GFAP):}

The cerebellar cortex was stained immunohistochemically with the anti-GFAP antibody to elucidate the response of astrocytes to the neural degeneration in the different experimental groups. As regarding

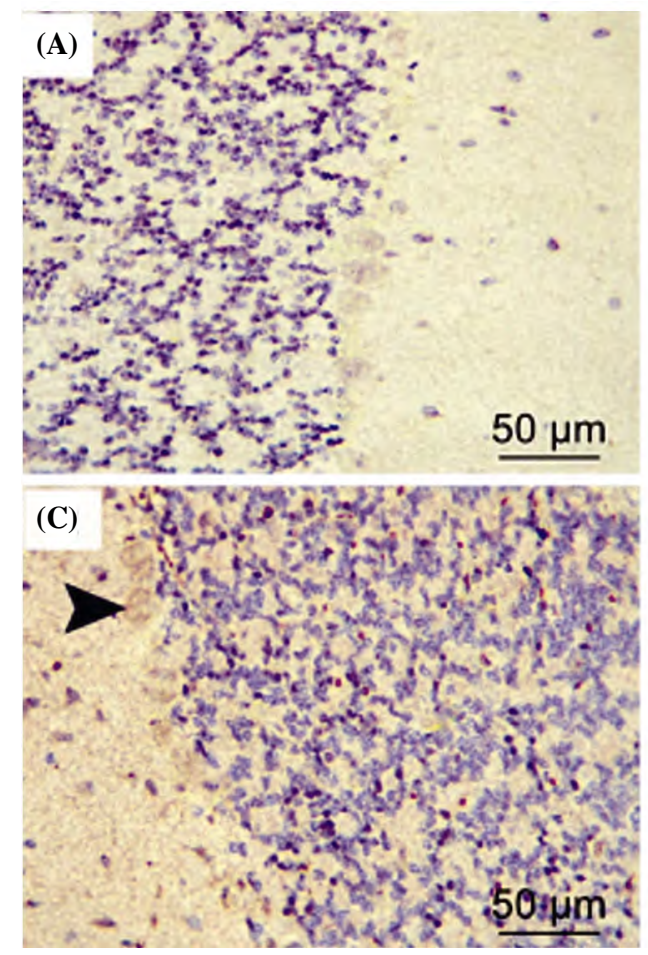

the control group, GFAP immune stained cerebellar sections showed faint staining of GFAP positive immunoreactive cells in all layers of the cerebellar cortex (Fig. 8a). In dimethoate group immune stained sections showed increase in the number of GFAP positive immunoreactive in all layers of the cerebellar cortex, as compared to the control group (Fig. 8b). The astrocytes showed long interdigitating processes. In dimethoate + quercetin group immune stained sections, showed an apparent decrease in the number of GFAP positive immunoreactive in all layers of the cerebellar cortex compared to dimethoate group (Fig. 8c). These results confirmed statistically Fig. (8d).

\section{Synaptophysin:}

As regarding the control group, immunoreactivity for SYP was represented in a form of coarsely fine beaded reactivity at the neuron surface of Purkinje cells of control rats. Reactive granules were also scattered in the molecular and granular cell layers matrix between the neurons (Fig. 9a). In dimethoate group faint SYP immunoreactivity along with the PCs, granular and molecular layers by grading the distribution along the entire cerebellar cortical area (Fig. 9b). In Dimethoate + Quercetin groupSynaptophysin immune stained sections, exhibited a significant intense SYP immunoreactions around the PCs in comparison with dimethoate treated group (Fig. 9c). These results confirmed statistically Fig. (9d).
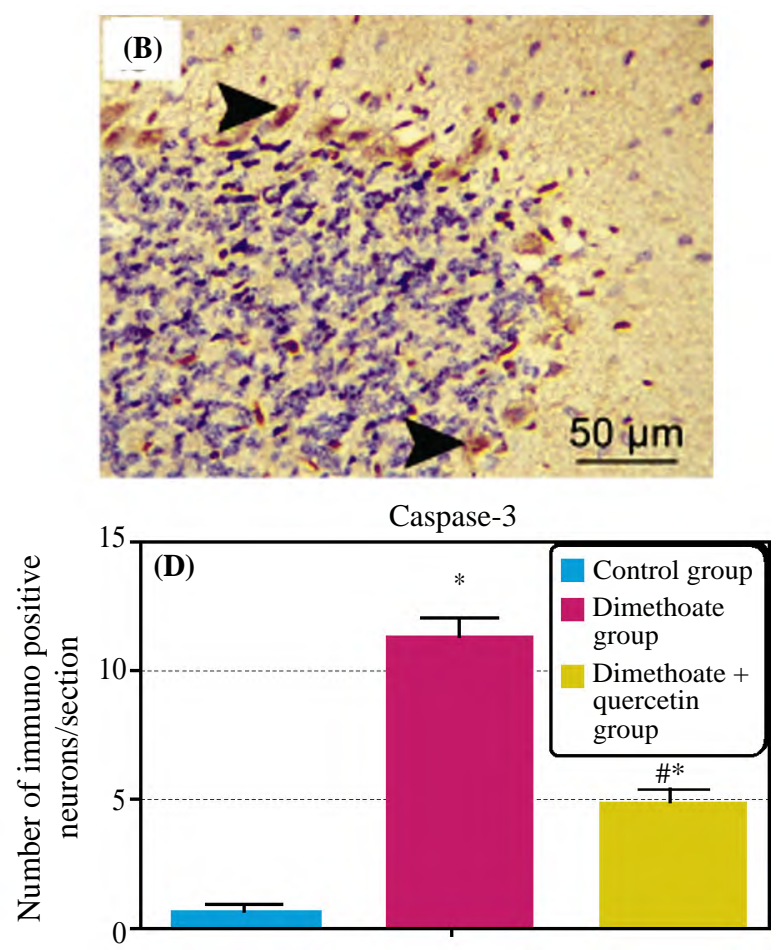

Fig. (7): Photomicrographs of the cerebellar cortex of the control (A), Dimethoate treated (B) and dimethoate + quercetin treated (C) groups immunoreactivity for caspase-3. Arrow head illustrates caspase -3 positive immunoreaction neurons. (d) Bar chart showing the quantitative analysis of the number of caspase-3 immunopositive neurons/ section. Statistical analysis was performed using one-way ANOVA, followed by Tukey's post hoc test. Values are represented as the mean $\pm \mathrm{SE}(\mathrm{n}=8)$. \#Significant difference compared to the control group, $p<0.05$. *Significant difference compared to the dimethoate treated group, $p<0.05$. Immunoperioxidase technique for caspase-3, $\mathrm{x} 50 \mu \mathrm{m}, \mathrm{x} 400$. 

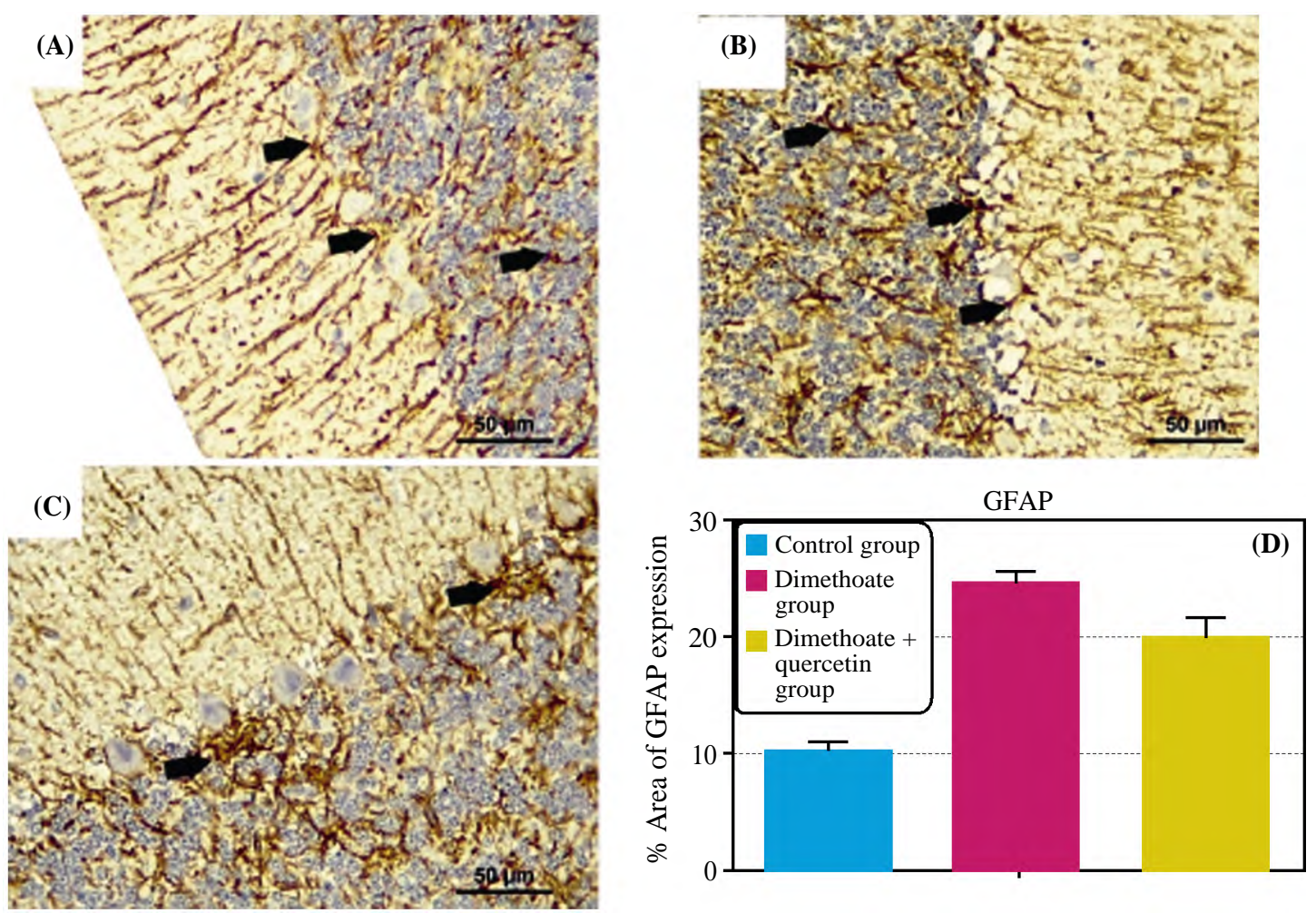

Fig. (8): Photomicrographs of the cerebellar cortex of the control (A), dimethoate treated (B) and dimethoate + quercetin treated (C) groups immunoreactivity for GFAP. Thick arrow illustrates positive immunostaing astrocytes. Bar chart demonstrating the Area \% of GFAP positive astrocyte in cerebral cortex of the different experimental groups. Statistical analysis was carried out using one-way ANOVA, followed by Tukey'spost hoc test. Values are represented as the mean $\pm \mathrm{SE}(\mathrm{n}=8)$. \# Significant difference compared to the control group, $p<0.05 .{ }^{*}$ Significant difference compared to the dimethoate treated group, $p<0.05$. Immunoperioxidase technique for GFAP, x $50 \mu \mathrm{m}, \mathrm{x} 400$.
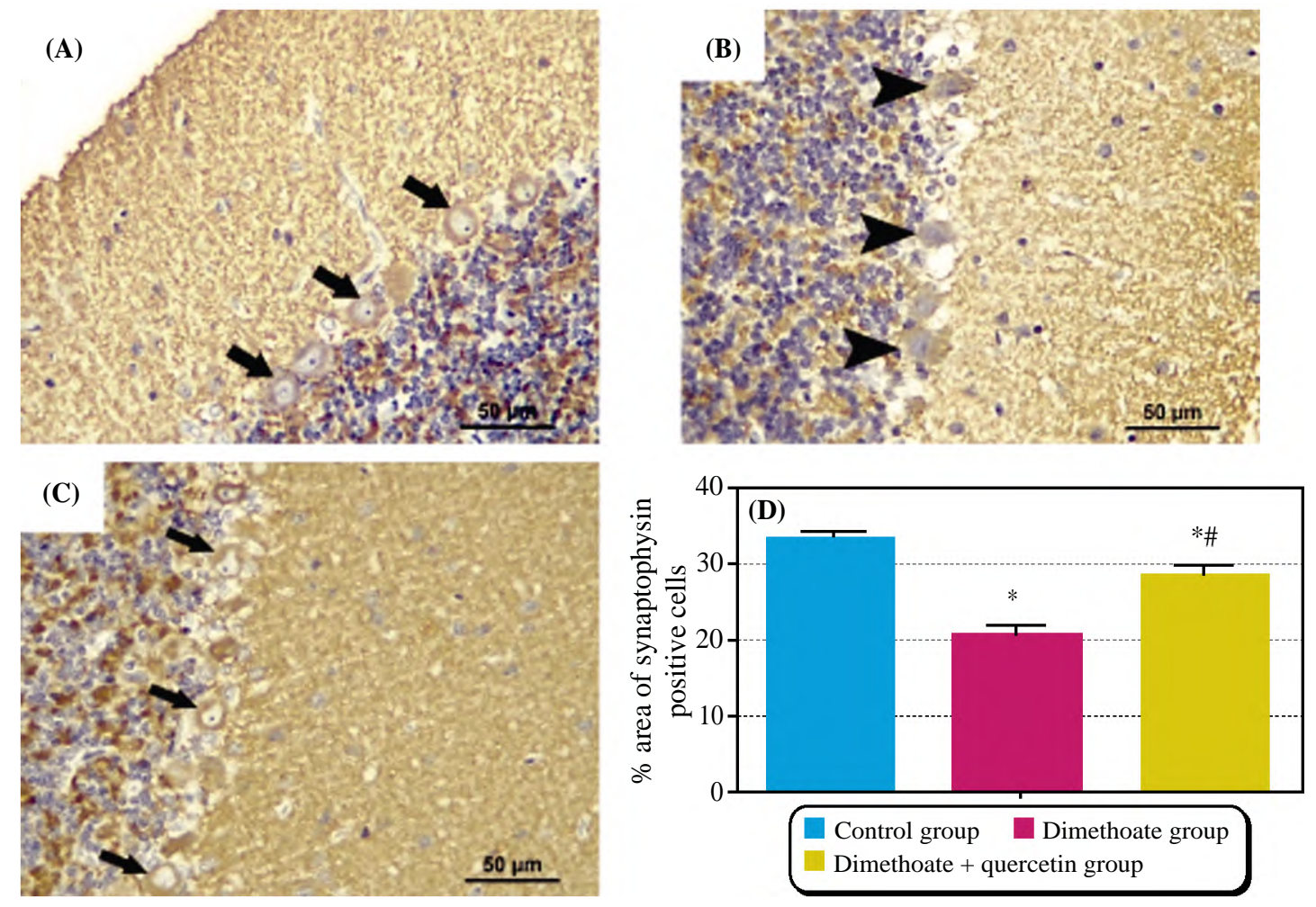

Fig. (9): Photomicrographs of the cerebellar cortex of the control (A), Dimethoate treated (B) and Dimethoate + Quercetin treated (C) groups immunoreactivity for synaptophysin. Coarsely fine beaded reactivity at the neuron surface of PCs (arrows) and faint immunoreactivity at the surface of PCs (arrow head). Bar chart demonstrating the Area \% of GFAP positive astrocyte in cerebral cortex of the different experimental groups. Statistical analysis was carried out using one-way ANOVA, followed by Tukey'spost hoc test. Values are represented as the mean \pm $\mathrm{SE}(\mathrm{n}=8)$. \#Significant difference compared to the control group, $p<0.05$.* Significant difference compared to the dimethoate treated group, $p<0.05$. SYP immunoreactivity $\mathrm{x} 400$. 


\section{Morphometrical results:}

Thickness of all layers of the cerebellar cortex (n):

Statistically a significant decrease in the thicknesses of the MCL, PCL and GCL was evident in the dimethoate treated group when compared with the control one.
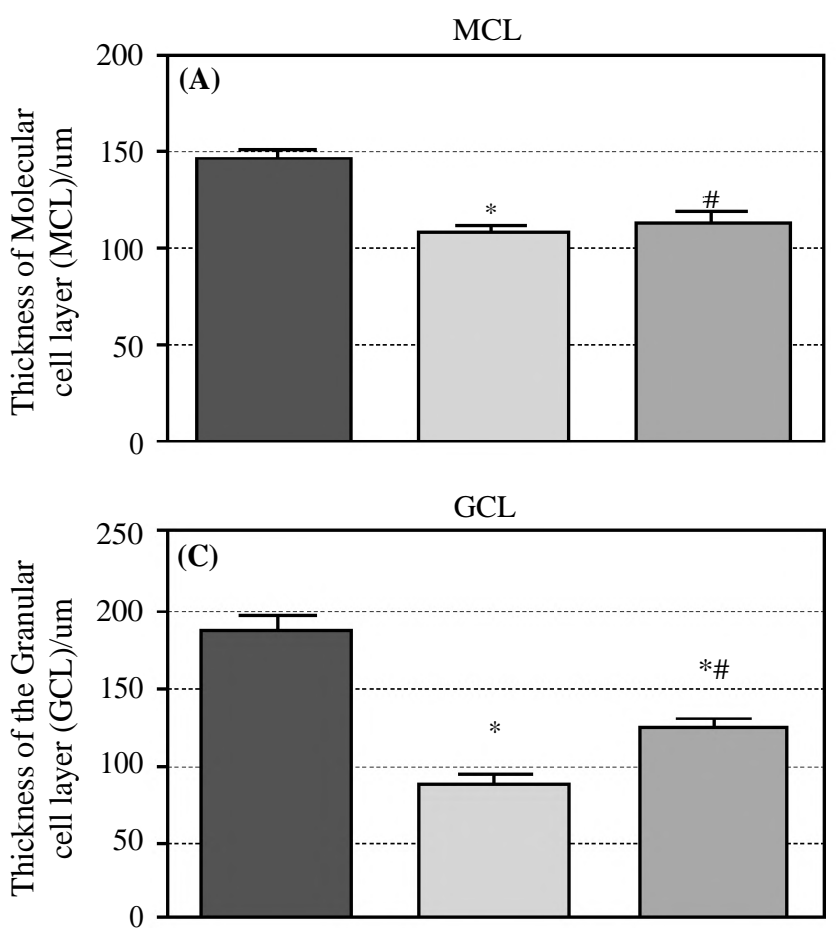

Discussion

Dimethoate is a commonly used insecticide and acaricide; it is habitually used as systemic and contact pesticide. It is used on agricultural harvests and patterned plants to control insects and pets. Dimethoate is one of the most essential organophosphorus insecticides that used in agriculture and also inside for control of houseflies [31].

In the current study, rats treated with dimethoate showed signs of toxicity represented by irritability, erected furs, suspended tail, itching, startle response, and crawling gait as a result of splaying of the hind limbs could be observed. Our results agreed with previous studies on animals exposed to lambdacyhalothrin insecticide $[32,33]$.

In addition, there was a significant decrease in body weight in the test groups $(p<0.05)$ when comparing the final weight to the initial body weight. This data suggests that the effects of dimethoate on body weight and body composition could be mediated through changes in food intake. Also, these results were in agreement with Aroonvilairat et al., [34] who stated that the body weights
Administration of Dimethoate + Quercetin resulted in a significant increase in the thicknesses of these layers when compared to dimethoate treated group. However, it was significantly decreased than control group only in GCL, not in PCL and MCL (Fig. 10).
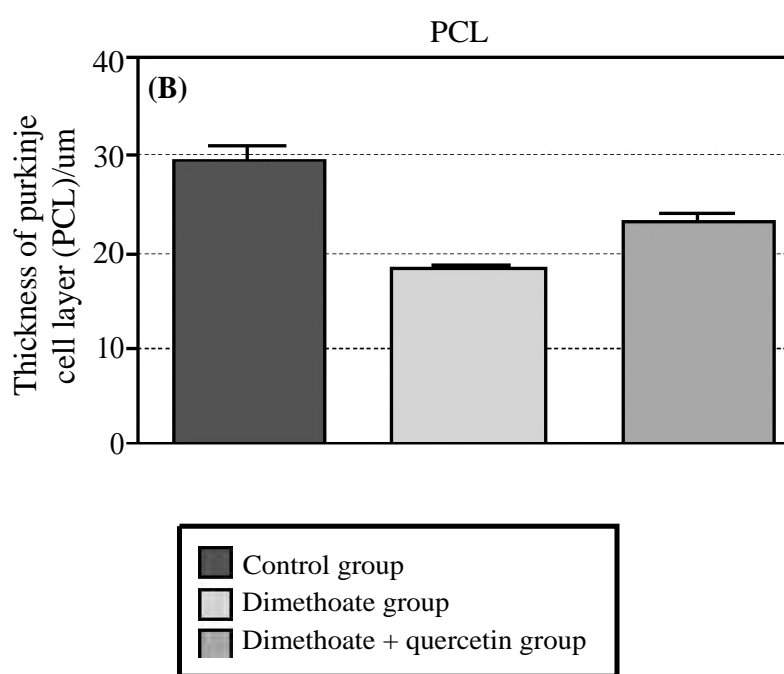

Fig. (10): Bar chart showing the comparison of the mean thickness of MCL, PCL and GCL among the different experimental groups, Control, dimethoate and dimethoate quercetin treated groups. Statistical analysis was carried out using one-way ANOVA, followed by Tukey'spost hoc test. Values are represented as The mean $\pm \mathrm{SE}(\mathrm{n}=8)$ \# Significant difference compared to the control group, $p<0.05$. *Significant difference compared to the MTX treated group, $p<0.05$.

of the groups that treated with chlorpyrifos, CYP and captan, were significantly decreased. The obtained results were in accordance with the previous studies $[35,36]$ who reported that administration of OP could suppress the growth rate through their suppression effects on the appetite center leading to decrement in food consumption. Other study explained the lower body weight via the mechanism involving disturbance in metabolic enzymes [37].

Igho \& Afoke [38] explained these clinical signs as a result of peripheral nervous system excitation. Dimethoate acts through irreversible inhibition to acetylcholinesterase enzyme leading to accumulation of acetylcholine at neuromuscular junction and in the autonomic and central nervous system which consequently affects conduction of nerve impulse. The current study confirmed the previous findings that there was a significant decrement in acetylcholinesterase enzyme activity as it is considered a standard biomarker to study neurotoxic effects of pesticides and this in accordance with Ali et al., [39]. 
Additionally, Marigoudar et al., [40] documented the inhibition of AChE activity and the buildup of acetylcholine (ACh) producing prolonged excitatory postsynaptic potential. This results in repeated, uncontrolled firing of neurons leading to hyperstimulation of the nerve and muscle fibers then subsequently tetany, paralysis, and eventually death.

The neurological tissue has a high rate of oxidative metabolism, consuming about $20 \%$ of the cardiac output. Since it is rich in polyunsaturated fatty acids (PUFAs), the brain is especially vulnerable to oxidative stress [41]. In the present study, rat's exposure to dimethoate resulted in a significant increase in lipid peroxidation and protein oxidation as indicated by the significant increase in MDA content, this was in agreement with Amara et al., [42] and Ali et al., [39]. Also, previous reports indicated that dimethoate caused cellular injury, lipid peroxidation, free radicals release, and oxidative stress in rats [6]. Also, El-Halwagy and Zaki [43] reported enhanced lipid peroxidation and increased MDA level in male albino rats intoxicated with organophosphorus (Diazinon) and pyrethroid (deltamethrin) in commercial formulation.

Upon histological examination of the control rats, the cerebellar cortex tissue presented normal histoarchitecture as reported by previous study $[42,44]$

In the present study, administration of dimethoate caused an evidence of structural changes in the rat cerebellar cortex mainly in the Purkinje cell layer. The Purkinje cells and granule cells appeared with dark (pyknotic) nuclei and vacuolation. These pyknotic nuclei might be a result of an irreversible condensation of chromatin in cells undergoing programmed cell death or apoptosis [45]. The vacuolation appeared within the granular cell layer and Purkinje cell layer were described as spongiform changes [46]. Other studied considered this vacuolation as a type of cellular defense mechanism against neurotoxins within the cerebellar cortex [47]. This was in agreement with the results of another study that reported a disorganized Purkinje cell layer and loss of Purkinje cells after metanil yellow administration [48].

These results were also in line with a previous dimethoate neuro-pathological study, which documented that under microscopic examination severe distortion in cellular architecture were observed in cerebral cortex of dimethoate treated rats [42].

Ali, et al., [39] . Explained that histological alterations in the cerebellar cortex under the influ- ence of dimethoate was mainly attributed to its oxidative damage.

Neurotoxins are famous risk factors for chronic neurodegenerative diseases, although molecular mechanisms engaged in the pathogenesis of diseases still indistinct, oxidative stress, excitotoxicity, inflammation and apoptosis have been involved as potential causes on neurodegeneration [49] Pyknosis was further confirmed by caspase $3 \mathrm{im}$ munohistochemical stain for apoptosis. In apoptotic neurodegeneration, the caspase family plays an essential role. Among caspase cascades, caspase3 is the major player in apoptosis and plays a key role in apoptosis [50]. A main result of this work was that dimethoate treatment significantly increased the number of degenerated neuronal cells represented by increased caspase- 3 immune positive neurons. The results of the present study were confirmed by the results obtained by Ali et al., [39] who reported increased apoptosis in the neuronal cells of cerebral cortex of deltamethrin \& dimethoate treated rats.

Elhalwagy et al., [51] explained that the released oxygen free radicals are implicated in destabilization and disintegration of cell membrane leading to cell death and apoptosis. Yuan \&Yankner [52] also, concluded that dimethoate induced oxidative stress in cerebellum is also implicated in histopathological changes and are attributed to inflammation, necrosis, or accelerated apoptosis.

In this study, immunohistochemical localization of GFAP was performed to inspect the allocation of astrocytes and their response to neuronal degeneration or injury [29]. The area percentage $(\%)$ of GFAP immunoreactivity was highly significantly increased as compared with control group. GFAP is an intermediate filament protein known to be specifically expressed in astrocytes, the glial cells that are responsible for repairing and scarring of the brain following injuries $[\mathbf{5 3 , 5 4}]$. The increase in GFAP expression has been documented as a biomarker of neurotoxicity [55], whereas exposure to any neurotoxic substances stimulates astrocytes' proliferation and hypertrophy with subsequent increase in the synthesis of GFAP leading to vigorous astrogliosis which is a compensatory neuroprotective process $[\mathbf{5 6 , 5 7 ]}$.

Synaptophysin (SYP) is an abundant membrane protein of synaptic vesicles. It is an immunohistochemical marker of axonal damage [58]. SYN is mainly localized at the synapses of the axons of granular cells and dendrites of Purkinje cells in the cerebellar cortex [59]. Most studies have assessed SYN as a measure of synaptic integrity [60] 
In the present work, SYN reactivity was represented in a form of coarsely fine beaded reactivity at the neuron surface Purkinje cells of control rats. Reactive granules were also scattered in the molecular and granular cell layers matrix between the neurons. On the contrary, decreased SYP immunoreactivity after treatment with dimethoate. This was also confirmed by the morphometric analysis, as there was a significant decrease in the area \% of synaptophysin expression in dimethoate group compared to control group. These results were in accordance with El-Beltagy et al., [61] and rahmy \& Hassona [62].

Ferrali et al., [16] reported that weak SYN reactivity indicates abnormal axon transport and impaired synaptic function resulting in cognitive deficits, the decreased expression of SYN could be due to a possible inhibition of SYN protein biosynthesis through DNA fragmentation induced by deltamethrin metabolites.

Quercetin supplementation along with dimethoate treatment exhibited no sign of toxicity and this was explained by a significant increase in the activity of acetylcholinesterase enzyme and decrease in the level of acetylcholine. This finding was in agreement withSandhir and Mehrotra [63] \& Chakraborty et al., [64] who reported that quercetin supplementation to chlorpyrifos treated animals decreased the level of acetylcholine and increased the acetylcholinesterase activity which is possibly due to antioxidative potential of quercetin that confirms the attack of reactive oxygen species generated by metabolism of chlorpyrifos.

Further, quercetin supplementation along with dimethoate treatment and revealed a significant increase in body weight in comparison with the dimethoate administered group, and this was in line with Fereidounni and Dhawan [21] whose study documented a seen increase in body weights following quercetin supplementation is reasonably due to antioxidative action of phenolic groups of quercetin which could contain reactive oxygen species and prevented oxidative damage.

Furthermore, result that confirmed the antioxidant effect of the quercetin in this study was a significant decrease in tissue MDA level which reflected the decrease of the lipid peroxidation. This was in accordance with Arredondo et al., [65] who stated that the quercetin pretreatments obviously exhibited to decrease the levels of lipid peroxidation thus demonstrating the neuroprotective effect of quercetin in stimulating the antioxidant defense mechanisms by putting off the lipid peroxidation in cellular membrane.
Additionally, Gargouri et al., [66] revealed that decreasing the level of MDA with quercetin supplementation and explained the antioxidant effect of quercetin may directly scavenge free radicals or modulate the biochemical markers of oxidative stress and antioxidant enzymes. Also, Saw, et al., [67] stated that quercetin has been shown to counteract oxidative stress-induced cellular damage by activating the Nrf2 - ARE pathway.

Accordingly, the antioxidant effect of the quercetin is reflected on the histological structure of the rat cerebellar cortex where most of Purkinje cells retained their normal characters. These results were in a line with Haq \& Al Amro [68] who stated that, the pretreatment of quercetin with $100 \mathrm{mg} / \mathrm{ml}$ showed a remarkable protective effecton the overall morphology and viability of neuronal cells. Also, Fereidounni and Dhawan [21] reported that, the histological changes induced by Organophosphate Chlorpyrifos were alleviated by supplementation of quercetin.

Furthermore, in dimethoate + quercetin group, there was a significant down regulation in Caspase3 apoptotic marker compared to dimethoate group. This result was explained by Leyton et al., [69] who stated that the neuroprotective effects of quercetin may also involve activation of sirtuins (SIRT1), which would lead to suppression of Baxdependent apoptosis and repression of multiple proapoptotic transcription factors.

Additionally, GFAP immune expression revealed a significant decrease in its area percent compared to the dimethoate group. These results were in agreement with Khan et al., [70] who documented that quercetin treatment along with $\mathrm{Li}$ popolysaccharide significantly declared the GFAPpositive cells and immunofluorescence reactivity compared to Lipopolysaccharide - treated mice.

Moreover, this finding enhanced bySharma et al., [5] who reported that some isoflavones are suggested to reduce microglial activation and subsequent release of proinflammatory factors. Chinta et al., [71] stated that quercetin also inhibits cytokine production by astrocytes.

Furthermore, a significant elevation in immunoreactivity against SYP was detected which was indicating a better synaptic preservation. This result in a line with Khan et al., [70] who stated that quercetin treatment significantly increased the immunofluorescence reactivity of SNAP-23 in the cortex and dentate gyrus region of the hippocampus compared to the Lipopolysaccharide treated group of adult mice. 


\section{Conclusion:}

Quercetin has a neuroprotective effect against the induced oxidative stress and neuronal injury by dimethoate administration. The effect of quercetin on the enhancement of neuronal survival and viability was most probably related to its antioxidant capacity and prevention of ROS generation. These results further accentuate the therapeutic potential of quercetin and the importance of taking quercetin enriched foods and marketed supplements, in order to prevent the neuronal loss in case of organophosphorus poisoning.

\section{Recommendations:}

Accordingly, on the basis of this work, it is recommended that the Ministry of Agriculture and Ministry of Health should be cooperated, recommend and engorge the people exposed to organophosphorus to intake quercetin enriched foods and marketed supplements.

\section{Conflicts of Interest:}

The authors have no conflicts of interest to declare.

\section{References}

1- SANDLER and HILARY A.: Integrated Pest Management. Cranberry Station Best Management Practices, 1: 12-15, 2010.

2- MARONI M., COLOSIO C., FERIOLI A. and FAIT A.: Biological Monitoring of Pesticide Exposure: A. Review. Toxicology, 7: 1-118, 2000.

3- COSTA L.G.: Current Issues in Organophosphate Toxicology. ClinicaChimica Acta, 366: 1-13. https://doi.org /10. 1016/j.cca. 2005. 10.008, 2006.

4- HALLIWELL B. and GUTTERIDGE J.M.C.: Cellular Responses to Oxidative Stress: Adaptation, Damage, Repair, Senescence and Death. Free Radicals in Biology and Medicine, 4: 187-267, 2007.

5- SHARMA P. and DUBEY R. S.: Involvement of Oxidative Stress and Role of Antioxidative Defense System in Growing Rice Seedlings Exposed to Toxic Concentrations of Aluminum. Plant Cell Reports, 26: 2027-2038. https: //doi.org/10.1007/s00299-007-0416-6, 2007.

6- SHARMA P. et al.: Organophosphorus Compounds and Oxidative Stress: A Review. Toxicological \& Environmental Chemistry, 96: 681-698. https://doi.org /10.1080 /02772248. 2014. 972045, 2014.

7- GOEL V., BUCHEL C., FRITH C. and DOLAN R.J. Dissociation of mechanisms underlying syllogistic reasoning. Neuroimage. Nov, 12 (5): 504-14, 2000.

8- MANSOUR S.A. and MOSSA A.H.: Adverse effects of lactational exposure to chlorpyrifos in suckling rats. Hum Exp Toxicol. Feb., 29 (2): 77-92. doi:10.1177/ 0960327109 357276. Epub 2009 Dec 22, 2010.

9- ELSHARKAWY E.E., YAHIA D. and EL-NISRB N.A.: Sub-chronic exposure to chlorpyrifos induces hematolog- ical, metabolic disorders and oxidative stress in rat: Attenuation by glutathione Environmental Toxicology and Pharmacology, Volume 35, Issue 2, Pages 218-227, 2013.

10- LOBNAEZZI L., SALAH I.B., HAOUAS Z., SAKLY A., GRISSA I., CHAKROUN S., KERKENI E., HASSINE M., MEHDI M. and CHEIKH H.: Histopathological and genotoxic effects of chlorpyrifos in rats, Environ Sci. Pollut Res., DOI 10.1007/s11356-015-5722-x, 2016.

11- ASTIZ M., ALANIZ M. and MARRA C.: Antioxidant defense system in rats simultaneously intoxicated with agrochemicals. Environmental toxicology and pharmacology, 28: 465-73. 10.1016/j.etap. 2009.07.009, 2009.

12- SAAFI E., LOUEDI M., ELFEKI A., ZAKHAMA A., NAJJAR M., HAMMAMI M. and ACHOUR L.: Protective effect of date palm fruit extract (Phoenix dactylifera L.) on dimethoate induced-oxidative stress in rat liver. Experimental and toxicologic pathology: official journal of the Gesellschaft für Toxikologische Pathologie, 63: 43341. 10.1016/j.etp.2010.03.002, 2010.

13- LAL C.S., KUMAR V., ANJAN A., DAS V.N., KUMAR N., KISHORE K. and BHATTACHARYA S.K.: Evaluation of Cholinesterase Level in an Endemic Population Exposed to Malathion Suspension Formulation as a Vector Control Measure. Memórias do Instituto Oswaldo Cruz, 99, 219.https://doi.org/10.1590/S0074-02762004000200 018,2004

14- LEE P. and TAI D.Y.: Clinical Features of Patients with Acute Organophosphate Poisoning Requiring Intensive Care. Intensive Care Medicine, 27: 694. https://doi.org/ 10.1007/s001340100895, 2001

15- RICE-EVANS C.A., MILLER N.J., BOLWELL P.G., et al.: The relative antioxidant activities of plant derived polyphenolic flavonoids. Free. Radic. Res., 22: 375-383, 1995.

16- FERRALI M., SIGNORINI C., CICCOLI L., et al.: Protection of erythrocytes against oxidative damage and autologous immunoglobulin $\mathrm{G}(\mathrm{IgG})$ binding by iron chelator fluor-benzoil-pyridoxal hydrazone. Biochem Pharmacol, 59: 1365-1373, 2000.

17- RICE-EVANS C.A., MILLER N.J. and PAGANGA G.: Structure-antioxidant activity relationships of flavonoids and phenolic acids. Free. Radic. Biol. Med., 20: 933-956, 1996.

18- WANG L., T.U Y.C., LIAN T.W., HUNG J.T., YEN J.H and WU M.J.: Distinctive antioxidant and antiinflammatory effects of flavonols. J. Agric. Food. Chem., 54: 9798 9804, 2006

19- XIAO X., SHI D., LUI L., WANG J., XIE X., KANG T. et al.: Quercetin suppresses cyclo- oxygenase-2 expression and angiogenesis through inactivation of P300 signaling. Plos ONE, 6: e22934, 2011.

20- World Health Organization. (2010). The WHO recommended classification of pesticides by hazard and guidelines to classification, 2009.

21- FEREIDOUNNI S. and DHAWAN D.K.: Understanding the role of quercetin during neurotoxicity induced by Chlorpyrifos, The Journal of Phytopharmacology, 7 (1): $33-39,2018$ 
22- ALTUN M.A., OZAYDIN A., ARKAN H., DEMIRYAS S., AKBAS F., BAHTIYAR N. and ONARAN I.: Anesthesia may alter mRNA expression of certain wound healing associated genes in dermal wound environment of the rats, Molecular Biology Reports, Volume 46, Issue 3, pp 2819-2827, 2019.

23- OHKAWA H., OHISHI N. and YAGI K.: Assay for lipid peroxides in animal tissues by thiobarbituric acid reaction. Analytical Biochemistry, 95 (2) pp. 351-358, 1979.

24- ELLMAN G.L., et al.: A new and rapid colorimetric determination of acetylcholiesterase activity. Biochemical Pharmacology, 7 (2): 88-95, 1961.

25- KAUR S., SINGLA N. and DHAWAN D.K.: Neuroprotective potential of quercetin during chlorpyrifos induced neurotoxicity in rats, Drug and Chemical Toxicology, DOI: 10.1080/01480545.2019.1569022, 2019.

26- BANCROFT J.D. and COOK H.C.: Manual of histological techniques and diagnostic applications. Churchill Livingstone, Edinburgh, pp. 263-325, 1994.

27- WU J., GORMAN A., ZHOU X., et al.: Involvement of Caspase-3 in Photoreceptor Cell Apoptosis Induced by In Vivo Blue Light Exposure. Investigative Ophthalmology \& Visual Science, 43 (10): 3349-3354, 2002.

28- MARTIN P.M. and O'CALLAGHAN J.P.: A direct comparison of GFAP immunocytochemistry and GFAP concentration in various regions of ethanol-fixed rat and mouse brain. Journal of Neuroscience Methods, 58 (12): 181-192, 1995

29- CHEN H. and WEBER A.J.: Expression of glial fibrillary acidic protein and glutamine synthetase by müller cells after optic nerve damage and intravitreal application of brain derived neurotrophic factor. Glia, 38 (2): 115-125, 2002.

30- DAN C., JIAN-BIN T., HUI W., et al.: Synaptophysin Expression in Rat Retina Following Acute High Intraocular Pressure. Acta. Histochem. Cytochem., 41 (6): 173-178, 2008.

31- HUSSAIN L.A.: Role of oxidative stress in organophosphate insecticide toxicity-short review. Pest Biochem. Physiol., 98: 145-150, 2010.

32- ABDEL-MOBDY Y.E. and ABDEL-RAHIM E.A.: Toxicological influences of lambda cyhalothrin and evaluation of the toxicity ameliorative effect of pomegranate in albino rats, global. Veterinaria, 14 (6): 913-921, 2015.

33- MANI V.M., AHMED A.N., ALI A.L., GOKULAKRISHNAN A., VINOTH K. and HUSSAIN A.A.: Hepatoprotective effect of quercetin on lambdacyhalothrin induced hepatotoxicity in male Wistar rats. Int. J. Sci. Humanit, 2: 401-416, 2016.

34- AROONVILAIRAT S., TANGJARUKIJ C., SORNPRACHUM T., CHAISURIYA P., SIWADUNE T. and RATANABANANGKOON K.: Effects of topical exposure to a mixture of chlorpyrifos, cypermethrin and captan on the hematological and immunological systems in male Wistar rats, Environ Toxicol. Pharmacol., 59: 53-60. doi: 10.1016/j.etap.2018.02.010. Epub 2018 Mar 2, 2018.

35- KALENDER S., KALENDER Y. and DURAK D.: Methyl parathion induced nephrotoxicity in male rats and protective role of vitamins C and E. Pestic. Biochem. Physiol., 88: 213-218, 2007
36- UZUNHISARCIKLI M., KALENDER Y. and DIRICAN K.: Acute, subacute and subchronic administration of methyl parathion-induced testicular damage in male rats and protective role of vitamins $\mathrm{C}$ and E. Pestic. Biochem. Phys., 87: 115-122, 2007.

37- ISSAM C., INTISSAR G., FATMA B., YAHIA H.M. SAMIH, et al.: Oxidative stress, biochemical and histopathological alterations in the liver and kidney of female rats exposed to low doses of deltamethrin (DM): A molecular assessment. Biomed. Environ. Sci., 25: 672-683, 2012.

38- IGHOI K. and AFOKE O.E.: A histomorphologic analysis of pyrethroid pesticide on the cerebrum and cerebellum of adult albino rats. Journal of Experimental and Clinical Anatomy, 13 (2): pp. 54, 2014.

39- ALI M., GOMAA M. and MOHAMMED Z.: Study of chronic toxic effect of deltamethrin and dimethoate on brain of adult male albino rats. Zagazig Journal of Forensic Medicine, 15 (1): 29-46, 2017.

40- MARIGOUDAR S.R., AHMED R.N. and DAVID M. Cypermethrin induced: In vivo inhibition of the acetylcholinesterase activity in functionally different tissues of the freshwater teleost, Labeorohita (Hamilton). Toxicological and Environ Chemistry, 91 (6) pp. 1175-1182, 2009.

41- WANGER B.A., BUETTNER G.R. and BURNA G.P.: Free radical mediated peroxidation in cells: Oxidability is a function of cell lipid bis-allylic hydrogen content, Biochemistry, 33: 4449-4453, 1994.

42- AMARA I., SOUDANI N., HAKIM A., TROUDI A., ZEGHAL K.M., BOUDAWARA T. and ZEGHAL N.: Selenium and vitamin E, natural antioxidants, protect the cerebral cortex against dimethoate-induced neurotoxicity. Pesticide Biochemistery and Physiology, 101. 165-174, 2011.

43- EL-HALWAGY M.E.A. and ZAKI N.J.: Comparative study of pesticide mixture of organophosphate and pyrethroids in commercial formulation. Environ. Toxicol. Pharmacol., 28: 219-224, 2009.

44- AFIFI O.K.: Effect of sodium fluoride on the cerebellar cortex of adult albino rats and the possible protective role of vitamin B6: A light and electron microscopic study. Egypt. J. Histo., 32: 358-67, 2009.

45- VENKATARAMAN P., SELVAKUMAR K., KRISHNAMOORTHY G., MUTHUSAMI S., RAMESHKUMAR R., PRAKASH S. and ARUNAKARAN J.: Effect of melatonin on PCB (Aroclor 1254) induced neuronal damage and changes in $\mathrm{Cu} / \mathrm{Zn}$ superoxide dismutase and glutathione peroxidase- 4 mRNA expression in cerebral cortex, cerebellum and hippocampus of adult rats. Neurosci. Res., 66: 189-197, 2010.

46- HUSAIN S.M.D.: Neurohistological effects of lead on pons of adult albimo rat. GJRA, 4: 452-453, 2015.

47- ELUWA M.A., INYANGMME I.I., AKPANTAH A.O., EKANEM T.B., EKONG M.B., et al.: A comparative study of the effect of diet and soda carbonated drinks on the histology of the cerebellum of adult female albino Wister rats. Afr. Health. Sci., 13: 541-545, 2013.

48- SARKAR R.: Histopathological changes in the brain of metanil yellow treated albino rat (Rattus norvegicus). 
International Journal of Basic and Applied Medical Sciences, 3 (2): 256-258, 2013.

49- KHALATBARY A.R., GHAFFARI E. and MOHAMMADNEGAD B.: Protective Role of Oleuropein against Acute Deltamethrin Induced Neurotoxicity in Rat Brain. Iran. Biomed. J., 19 (4): 247-253, 2015.

50- BADSHAH H., ALI T. and KIM M.O.: Osmotin attenuates LPS-induced neuroinflammation and memory impairments via the TLR4/NFK signalling pathway. Sci. Rep., 6: 24493. doi: 10.1038/srep 2449, 2016.

51- ELHALWAGY M.E.A., DARWISH E.M. and ZAHER N. S.: Prophylactic effects of green tea polyphenols against liver and kidney induced by feitrothion insecticide. Pest. Biochem. Physiol., 91: 81-89, 2008.

52- YUAN J. and YANKNER A.: Apoptosis in the nervous system. Nature, 407: 802-809, 2016.

53- DER PERNG M.M., SU S.F., WEN T., GIBBON A.R., PRESCOTT M., BRENNER and QUINLAN R.A.: The Alexander disease-causing glial fibrillary acidic protein mutant, R416W, accumulates into Rosenthal fibers by a pathway that involves filament aggregation and the association of alpha B-crystallin and HSP27. Am. J. Hum. Genet., 79 (2): 197-213, 2006.

54- LI D.R., ISHIKAWA T., ZHAO D., MICHIUE T., QUAN L., ZHU B.L. and MAEDA H.: Histopathological changes of the hippocampus neurons in brain injury. Histol. Histopathol., 24 (9): 1113-1120, 2009.

55- CALLAGHAN J.P.O. and SRIRAM K.: Glial fibrillary acidic protein and related glial proteins as biomarkers of neurotoxicity, 4 (3): 433-42, 2005.

56- BORLONGAN C.V., YAMAMOTO M., TAKEI N., KUMAZAKI M., UNGSUPARKORN C., HIDA H., SANBERG P.R. and NISHINO H.: Glial cell survival is enhanced during melatonin induced neuroprotection against cerebral ischemia. FASEB J., 14 (10): 1307-1317, 2000.

57- BAYDAS G., OZER M., YASAR A., KOZ S.T. and TUZCU M.: Melatonin prevents oxidative stress and inhibits reactive gliosis induced by hyperhomocysteinemia in rats. Biochemistry (Mosc), 71: 91-95, 2006.

58- GUDI V., GAI L., HERDER V., TEJEDOR L.S., KIPP M., AMOR S. and STANGEL M.: Synaptophysin is a reliable marker for axonal damage. Journal of Neuropatholgy \& Experimental Neurology, 76 (2): 109-125, 2017.

59- LECLERC N., BEESLEY P.W., BROWN I., COLONNIER M., GURD J.W., et al.: Synaptophysin expression during synaptogenesis in the rat cerebellar cortex. J. Comp. Neurol., 280: 197-212, 1989.

60- MINGER S.L., HONER W.G., ESIRI M.M., MCDONALD B., KEENE J., NICOLL J.Á., CARTER J., HOPE T. and FRANCIS P.T.: Synaptic pathology in prefrontal cortex is present only with severe dementia in Alzheimer disease. J. Neuropathol. Exp. Neurol., 60: 929-36, 2001.
61- EL-BELTAGY A.B.M., ELBAKRYK A.M., ELGHAZALY M.M.A., ALI L S. and EL DAQAQQ N.H.M.: Adverse Effects of Deltamethrin On the Cerebellum of Mothers Rats and Their Offspring and The Possible Ameliorative Role of Melatonin. International Journal of Pure and Applied Zoology, Volume 7, Issue 3, 2019.

62- RAHMY T.R. and HASSONA I .A.: Immunohistochemical investigation of neuronal injury in cerebral cortex of cobra-envenomed rats. Journal of Venomous Animals and Toxins including Tropical Diseases, 10 (1): 53-76, 2004.

63- SANDHIR R. and MEHROTRA A.: Quercetin supplementation is effective in improving mitochondrial dysfunctions induced by 3-nitropropionic acid: Implications in Huntington's disease. Biochim. Biophys Acta., 1832 (3): 421, 2013.

64- CHAKRABORTY J.L., SINGH R., DUTTA D., NASKAR A., RAJAMMA U. and MOHANA KUMAR K.P.: Quercetin improves behavioral deficiencies, restores astrocytes and microglia, and reduces serotonin metabolism in 3 nitropropionic acid-induced rat model of Huntington's Disease. CNS. Neurosci. Ther. Jan., 20 (1): 10-9, 2014.

65- ARREDONDO C.F., ECHEVERRY J.A., ABIN-CARRIQ UIRY F., BLASINA K., ANTUNEZ D.P., JONES, et al.: After cellular internalization, quercetin causes Nrf2 nuclear translocation, increases glutathione levels, and prevents neuronal death against an oxidative insult, Free Radic Biol. Med., 49: pp. 738-747, 2010.

66- GARGOURI B., MANSOUR R.B., ABDALLAH F.B. ELFEKIH A., LASSOUED S. and KHALED H.: Protective effect of quercetin against oxidative stress caused by dimethoate in human peripheral blood lymphocytes. Lipids in health and disease, 10 (1): 149, 2011.

67- SAW C.L.L., GUOY, YANG AY, et al.: "The berry constituents' quercetin, kaempferol, and pterostilbene synergistically attenuate reactive oxygen species: Involvement of the Nrf2-ARE signaling pathway", Food and Chemical Toxicology, Vol., 72: pp. 303-311, 2014.

68- HAQ S.H. and ALAMRO A.A.: Neuroprotective effect of quercetin in murine cortical brain tissue cultures. Clinical Nutrition Experimental, 23: 89-96, 2019.

69- LEYTON L., HOTT M., ACUÑA F., et al.: "Nutraceutical activators of AMPK/Sirt1 axis inhibit viral production and protect neurons from neurodegenerative events triggered during HSV-1 infection", Virus Research, Vol., 205: pp. 63-72, 2015.

70- KHAN A., ALI T., REHMAN S.U., KHAN M.S., ALAM, S.I., IKRAM M. and KIM M.O.: Neuroprotective effect of quercetin against the detrimental effects of LPS in the adult mouse brain. Frontiers in Pharmacology, 9, 2018.

71- CHINTA S.J., LIEU C.A., DEMARIA M., LABERGE R.M., CAMPISI J. and ANDERSEN J.K.: Environmental stress, ageing and glial cell senescence: A novel mechanistic link to Parkinson's disease? J. Intern. Med., 273 (5): 429-36. doi: 10.1111/joim.12029, 2013. 


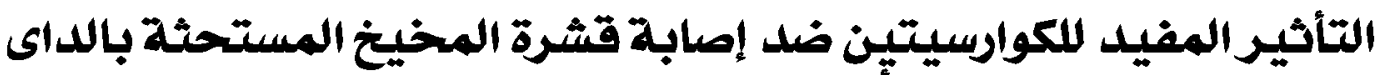

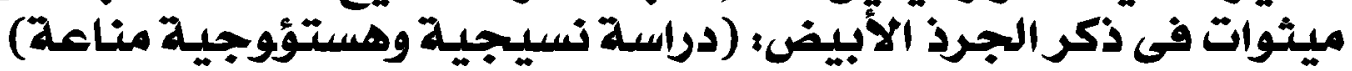

خلفية البحث: مركب الفوسفوالعضوى داى ميثوات هو مبيد يستخدم على نطاق واسع فى جميع انحاء العالم اللسيطرة على الديدان

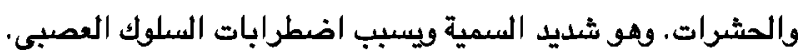

يعتبر الكوارسيتين فلافونويد طبيعى يوجد بغزارة في الفواكة والخضروات ويشتهر بخصائصة المضادة للاكسيدة وقدرتة على تحسين الإجهاد التاكسيدى وتعزيز بقاء الخلايا.

الهدف: تقييم السمية العصبية والتفيرات الهيكلية للقشرة الدمافية الناتجة عن داى ميثوات واستكثاف التأثير المحتمل. للحماية العصبية للكوارسستين.

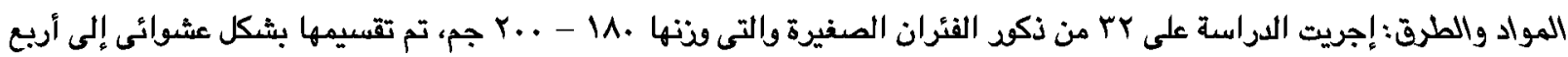

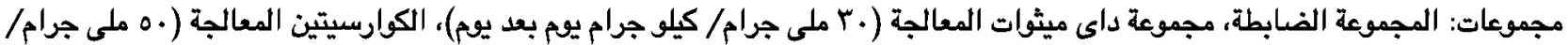

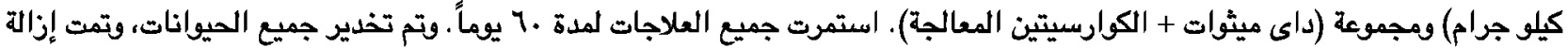
المخيخ لإعداد العينات للفصص ومه النسيجى، المناعى، والكيمياء الصيوية.

النتائج: كثفت النتائج عن وجود تسمم وإنخفاض كبير فى وذن الصيوانات المعالجة بالداي ميثوات والتى تصسنت بشكل ملحوظ عند التكميل

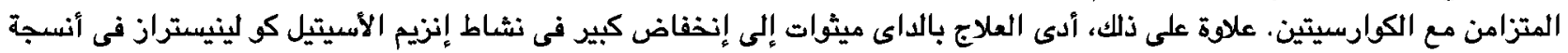

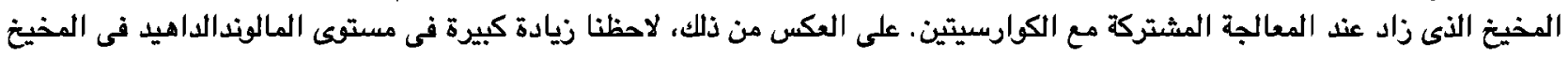
والتى إنخفض مستواه عند المعالجة المثتركة مع الكئه الكوارسيتين.

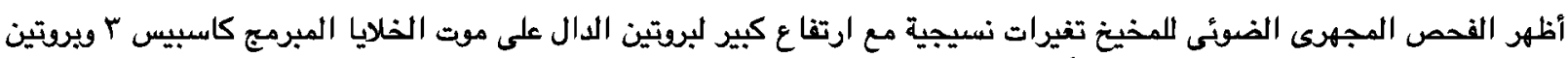

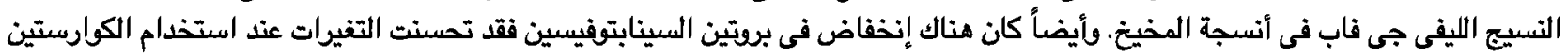
أثثاء التعرض اللداى ميثوات.

في الخلاصة نستنتج أن الكوارسيتين عند إستخدامه كتذخلوقائى من شأنه أن يوفر الحماية ضد السمية العصبية التى تسبيها داى ميثوات. 